\title{
Sistem Pendukung Keputusan Kelayakan Pemberian Kredit Dengan Metode TOPSIS
}

\author{
Ade Mubarok ${ }^{1}$, Himam Dwipratama Suherman ${ }^{2}$, Yudi Ramdhani ${ }^{3}$, Salman Topiq ${ }^{4}$ \\ 1,2,3,4 Universitas BSI \\ 1Email : ade.amb@bsi.ac.id \\ 2Email : himamdwi11@gmail.com \\ ${ }^{3}$ Email : yudiramdhani.yrm@gmail.com \\ ${ }^{4}$ Email : salmantofiq@gmail.com
}

\begin{abstract}
Abstrak
Koperasi syariah BMT ItQan merupakan salah satu koperasi dengan pengelolaan secara syariah, menyediakan produk simpanan, pembiayaan dan jasa keuangan syariah. Sistem pembiayaan yang diterapkan di Koperasi syariah BMT ItQan ini masih secara manual dalam prosesnya. Koperasi memberikan pembiayaan kepada anggotanya dengan ketentuan kriteriakriteria, dimana proses penilaian kriteria masih silakukan secara manual, sehingga keputusan yang dihasilkan masih kurang efektif dan akurat karena terkadang ada beberapa kriteria yang tidak ikut dipertimbangkan pada saat proses penilaian. Penggunaan Sistem Pendukung Keputusan dapat memudahkan pihak koperasi dalam pengambilan keputusan pemberian pembiayaan. Sistem Pendukung Keputusan ini dibuat menggunakan metode TOPSIS (Technique For Orders Reference by Similarity to Ideal Solution). Sistem Pendukung keputusan ini dibuat menggunakan bahasa pemrograman PHP dengan tools yang digunakan adalah Sublime Text 3 dan $\mathrm{MySql}$ untuk database yang menggunakan tools XAMPP. Hasil dari penelitian ini adalah sistem pendukung keputusan kelayakan pembiayaan yang dibangun sebagai alat bantu untuk penentuan kelayakan pembiayaan.
\end{abstract}

Kata Kunci: Sistem Pendukung Keputusan, TOPSIS, Pembiayaan

\begin{abstract}
Sharia Cooperative BMT ItQan is one of the cooperatives with sharia management, providing deposit products, financing and sharia financial services. The financing system which was implemented in the Sharia Cooperative BMT ItQan, is still manually in the process. The cooperative provides financing to its members with the provisions of the criteria, the criteria assessment process is still done manually, so the resulting decision is still less effective and accurate because sometimes there are some criteria that are not taken into consideration during the assessment process. Use of Decision Support Systems can facilitate cooperatives in making financing decisions. This Decision Support System was made using the TOPSIS (Technique For Orders Reference by Similarity to Ideal Solution) method. This decision support system is made using the PHP programming language with the tools used are Sublime Text 3. Adobe Photoshop as a program interface design and MySql for databases that use XAMPP tools. The results of this study are a support system for financing feasibility decisions that are built as a tool for determining the feasibility of financing.
\end{abstract}

\section{Key Word : Decision Support Sistem, TOPSIS, Financing}

\section{Pendahuluan}

Koperasi syariah BMT ItQan merupakan salah satu koperasi dengan pengelolaan secara syariah, menyediakan produk simpanan, pembiayaan dan jasa keuangan syariah. Koperasi ini memiliki 
beberapa jenis dari produk simpanan dan pembiayaan, dari produk pembiayaan terdapat 2 jenis yaitu pembiayaan kelompok dan pembiayaan perorangan. Ketentuan umum yang diterapkan dalam pembiayaan salah satunya adalah harus terdaftar sebagai anggota koperasi untuk dapat melakukan peminjaman, setelah menjadi anggota koperasi selanjutnya ada beberapa syarat dan kriteria agar anggota koperasi dapat memperoleh pinjaman atau pembiayaan dari pihak koperasi, selain itu juga harus melalui proses yang cukup panjang untuk dapat mendapatkan pinjaman.

Sistem pembiayaan yang diterapkan di Koperasi syariah BMT ItQan ini masih secara manual dalam prosesnya. Koperasi memberikan pembiayaan kepada anggotanya dengan ketentuan kriteriakriteria, dimana proses penilaian kriteria masih silakukan secara manual, dimana dalam penentuan pemberian pembiayaannya perhitungan masih dilakukan dengan menggunakan banyak berkas secara manual, apabila terjadi perubahan data atau informasi maka diperlukan waktu yang tidak sebentar, sehingga keputusan yang dihasilkan masih kurang efektif dan akurat karena terkadang ada beberapa kriteria yang tidak ikut dipertimbangkan pada saat proses penilaian, untuk memudahkan pihak koperasi dalam pengambilan keputusan pemberian pembiayaan, maka diperlukan Aplikasi Sistem Pendukung Keputusan.

Sistem Pendukung Keputusan Pemberian pembiayaan kredit dimaksudkan untuk membantu manajer dalam memberikan keputusan terhadap permohonan pembiayaan yang diajukan pemohon, karena untuk memutuskan diterima atau tidaknya permohonan pembiayaan yang diajukan oleh pemohon bukanlah suatu hal mudah, karena umumnya ada lima hal yang sering disebut Five C yaitu Character, Capacity, Capital, Collateral, Condition yang akan dijadikan pertimbangan untuk pemberian kredit (Listiyono, Sunardi, \& Khristianto, 2011).
Sistem pendukung keputusan pemberian pembiayaan kredit ini diterapkan dalam rangka untuk mengatasi kemungkinan masalah yang terjadi apabila ada kesalahan berupa ketidakakuratan data yang diperoleh pihak koperasi dalam proses penentuan pemberian pinjaman dapat mengakibatkan terjadi risiko kredit macet karena kredit yang macet ini merupakan suatu masalah komplek yang dapat menyebabkan kerugian. Sistem yang terkomputerisasi yang mendukung keputusan pihak manajer dirasa akan sangat membantu koperasi dalam berbagai aspek, dengan menerapkan sebuah sistem pendukung keputusan penentuan pemberian pembiayaan kredit tentunya akan sangat berguna bari koperasi. Sistem pendukung keputusan yang akan dikembangkan dalam penelitian ini menggunakan metode Technique for Order Preference by Similarity to Ideal Solution (TOPSIS) dalam melakukan pembobotan penerima kredit sehinga dapat memberikan solusi terhadap permasalahan yang ada.

The Technique for Order of Preference by Similarity to Ideal Solution (TOPSIS) adalah salah satu metode pengambilan keputusan multikriteria yang pertama kali diperkenalkan oleh Yoon dan Hwan. TOPSIS menggunakan prinsip bahwa alternatif yang terpilih harus mempunyai jarak terdekat dari solusi ideal positif dan jarak terpanjang (terjauh) dari solusi ideal negatif dari sudut pandang geometris dengan menggunakan jarak Euclidean (jarak antara dua titik) untuk menentukan kedekatan relatif dari suatu alternatif dengan solusi optimal. Solusi ideal positif didefinisikan sebagai jumlah dari seluruh nilai terbaik yang dapat dicapai untuk setiap atribut, sedangkan solusi ideal negatif terdiri dari seluruh nilai terburuk yang dicapai untuk setiap atribut. TOPSIS mempertimbangkan keduanya, jarak terhadap solusi ideal positif dan jarak terhadap solusi ideal negatif dengan mengambil kedekatan relatif terhadap solusi ideal positif (Ferdiansyah, Bachri, \& Harliana, 2015). 


\section{Sistem Pendukung Keputusan}

Sistem pendukung keputusan ialah proses pengambilan keputusan dengan bantuan media komputer dalam proses pengambil keputusan dengan menggunakan beberapa data dan model tertentu untuk menyelesaikan beberapa masalah yang tidak terstruktur. Sistem penunjang keputusan adalah sistem yang dapat membantu permasalahan dalam mengambil keputusan yang akurat dan tepat sasaran. Banyak permasalahan yang dapat diselesaikan dengan menggunakan sistem pengambilan keputusan (Nuris, 2017).

Sistem Pendukung Keputusan (SPK) biasanya dibangun untuk mendukung solusi atas suatu masalah atau untuk satu peluang. Aplikasi sistem pendukung keputusan digunakan dalam pengambilan keputusan. Aplikasi SPK menggunakan CBIS (Computer Based Information System) yang fleksibel, interaktif dan dapat diadaptasi, yang dikembangkan untuk mendukung solusi atas masalah manajemen spesifik yang tidak terstruktur (Nofriansyah, 2014).

\section{Technique For Orders Reference by Similarity to Ideal Solution (TOPSIS)}

Technique For Orders Reference by Similarity to Ideal Solution atau TOPSIS dikenalkan pertamakali oleh Yoon dan Hwang pada tahun 1981 untuk digunakan sebagai salah satu metode dalam memecahkan masalah multikriteria.

Metode TOPSIS mampu melakukan perangkingan terhadap alternatif terpilih. Dimana alternatif terpilih yang terbaik tidak hanya memiliki jarak terpendek dari solusi ideal positif, tetapi juga memiliki jarak terpanjang dari solusi ideal negatif. Solusi ideal positif diartikan solusi yang memaksimalkan atribut keuntungan (profit) dan meminimalkan atribut biaya (cost), sedangkan solusi ideal negatif diartikan dengan solusi yang meminimalkan atribut keuntungan(profit) dan memaksimalkan biaya (cost) (Kristiana, 2018).
Secara umum, prosedur TOPSIS mengikuti langkah-langkah:

1. Membuat matriks keputusan yang ternormalisasi.

2. Membuat matriks keputusan yang ternormalisasi terbobot.

3. Menentukan matriks solusi ideal positif dan matriks solusi ideal negatif.

4. Menentukan jarak antara nilai setiap alternatif dengan matriks solusi ideal positif dan matriks solusi ideal negatif.

5. Menentukan nilai preferensi untuk setiap alternatif.

TOPSIS membutuhkan rating kerja setiap alternatif $A_{1}$ pada setiap kriteria $C_{j}$ yang ternormalisasi dapat dilihat pada persamaan (1).

$$
r_{i j}=\frac{X_{i j}}{\sqrt{\sum_{i=1}^{m} X_{i j}^{2}}}
$$

Dengan $\mathrm{i}=1,2, \ldots ., \mathrm{m}$; dan $\mathrm{j} 1,2, \ldots, \mathrm{n} ; \mathrm{r}_{\mathrm{ij}}$ adalah matriks ternormalisasi [i][j] sedangkan $\mathrm{x}_{\mathrm{ij}}$ merupakan matriks keputusn [i][j].

Solusi ideal positif $\mathrm{A}^{+}$dan solusi ideal negatif $\mathrm{A}^{-}$dapat ditentukan berdasarkan rating bobot ternormalisasi $\left(\mathrm{y}_{\mathrm{ij}}\right)$ dapat dilihat pada persamaan (2). $\mathrm{Y}_{\mathrm{ij}}=\mathrm{w}_{\mathrm{i}} \cdot \mathrm{r}_{\mathrm{ij}}$;

Dengan $\mathrm{i}=1,2, \ldots, \mathrm{m}$; dan $\mathrm{j}=1,2, \ldots, \mathrm{n}$

$$
\begin{aligned}
& \mathrm{A}^{+}=\left(\mathrm{y}_{1}^{+}, \mathrm{y}_{2}{ }^{+}, \ldots ., \mathrm{y}_{\mathrm{n}}{ }^{+}\right) ; \\
& \mathrm{A}^{-}=\left(\mathrm{y}_{1}^{-}, \mathrm{y}_{2}{ }^{-}, \ldots ., \mathrm{y}_{\mathrm{n}}{ }^{-}\right) ; \\
& \text {Dimana } \mathrm{y}_{\mathrm{ij}} \text { adalah matriks }
\end{aligned}
$$

ternormalisasi terbobot [i][j] dan $\mathrm{w}_{\mathrm{i}}$ merupakan vektor bobot [i]. Agar dapat menghitung nilai solusi ideal terlebih dahulu harus menentukan apakah bersifat keuntukang (benefit) atau bersifat biaya (cost). Dimana jika j adalah atribut keuntungan (benefit) maka $\mathrm{y}_{j}{ }^{+}$adalah max $\mathrm{y}_{\mathrm{ij}}$ dan $\mathrm{y}_{\mathrm{j}}$ adalah min $\mathrm{y}_{\mathrm{ij}}$, sebaliknya jika $\mathrm{j}$ adalah atribut biaya (cost) maka $\mathrm{y}_{\mathrm{j}}{ }^{+}$adalah $\min \mathrm{y}_{\mathrm{ij}}$ dan $\mathrm{y}_{\mathrm{i}}^{-}$adalah $\max \mathrm{y}_{\mathrm{ij}}$.

Jarak antara alternatif $A_{i}$ dengan solusi ideal positif dapat dilihat pada persamaan (3). 
$\mathrm{D}_{\mathrm{i}}^{+}=\sqrt{\sum_{\mathrm{i}=1}^{\mathrm{m}}\left(\mathrm{y}_{\mathrm{i}}^{+}-\mathrm{y}_{\mathrm{ij}}\right)^{2}}$

$=1,2, \ldots . . \mathrm{m}$

Dimana $\mathrm{D}_{\mathrm{i}}^{+}$adalah jarak alternatif $\mathrm{A}_{\mathrm{i}}$ dengan solusi ideal positif, $\mathrm{y}_{\mathrm{i}}^{+}$merupakan solusi ideal positif [i] dan $\mathrm{y}_{\mathrm{ij}}$ adalah matriks normalisasi terbobot [i][j]. Untuk rumus jarak antara alternatif $A_{i}$ dengan solusi ideal negatif dapat dilihat pada persamaan (4).

$\mathrm{D}_{\mathrm{i}}^{-}=\sqrt{\sum_{\mathrm{j}=1}^{\mathrm{m}}\left(\mathrm{y}_{\mathrm{ij}}{ }^{-}-\mathrm{y}_{\mathrm{i}}{ }^{-}\right)^{2}}$

$=1,2, \ldots ., \mathrm{m}$

Dimana $\mathrm{D}_{\mathrm{i}}^{-}$adalah jarak alternatif $\mathrm{A}_{\mathrm{i}}$ dengan solusi ideal negatif, $\mathrm{y}_{\mathrm{i}}^{-}$adalah solusi ideal positif [i] dan $\mathrm{y}_{\mathrm{ij}}$ adalah matriks normalisasi terbobot [i][j].

Nilai preferensi untuk setiap alternatif $\left(V_{i}\right)$ dalat dilihat pada persamaan (5).

$$
\mathrm{V}_{\mathrm{i}}=\frac{\mathrm{D}_{\mathrm{i}}^{-}}{\mathrm{D}_{\mathrm{i}}{ }^{-}+\mathrm{D}_{\mathrm{i}}{ }^{+}} \quad ; \mathrm{i}=1,2, \ldots ., \mathrm{m}
$$

Dimana $V_{i}$ merupakan kedekatan setiap alternatif terhadap solusi ideal, $\mathrm{D}_{\mathrm{i}}^{+}$adalah jarak alternatif $\mathrm{A}_{\mathrm{i}}$ dengan solsi ideal positif dan $\mathrm{D}_{\mathrm{i}}^{-}$merupakan jarak alternatif $\mathrm{A}_{\mathrm{i}}$ dengan solusi ideal negatif. Nilai $V_{i}$ yang lebih besar menunjukkan bahwa alternatif $A_{i}$ lebih dipilih.

Tabel 1. Tabel Pemberian Nilai

\begin{tabular}{|l|l|}
\hline \multicolumn{1}{|c|}{ Nilai } & \multicolumn{1}{c|}{ Keterangan } \\
\hline 0 & Sangat Buruk \\
\hline 0.25 & Buruk \\
\hline 0.5 & Cukup \\
\hline 0.75 & Baik \\
\hline 1 & Sangat Baik \\
\hline
\end{tabular}

Tabel 2. Tabel Penilaian Indeks Rumah

\begin{tabular}{|l|l|}
\hline \multicolumn{2}{|c|}{ Indeks Rumah } \\
\hline $15-19$ & 1 \\
\hline $11-14$ & 0.75 \\
\hline $8-10$ & 0.5 \\
\hline $6-8$ & 0.25 \\
\hline $0-5$ & 0 \\
\hline
\end{tabular}

Tabel 3. Tabel Penilaian PPI Skor

\begin{tabular}{|l|l|}
\hline \multicolumn{2}{|c|}{ PPI Skor } \\
\hline $75-100$ & 1 \\
\hline $55-74$ & 0.75 \\
\hline $35-54$ & 0.5 \\
\hline $21-34$ & 0.25 \\
\hline $0-20$ & 0 \\
\hline
\end{tabular}

Tabel 4. Tabel Repayment Cap

\begin{tabular}{|l|l|}
\hline \multicolumn{2}{|c|}{ Repayment Cap } \\
\hline$>1000$ & 1 \\
\hline $751-1000$ & 0.75 \\
\hline $501-750$ & 0.5 \\
\hline $101-500$ & 0.25 \\
\hline $0-100$ & 0 \\
\hline
\end{tabular}

Tabel 5. Tabel Penilaian Kebutuhan Pembiayaan

\begin{tabular}{|l|l|}
\hline \multicolumn{2}{|c|}{ Repayment Cap } \\
\hline$>10000$ & 1 \\
\hline $8001-10000$ & 0.75 \\
\hline $5001-8000$ & 0.5 \\
\hline $2501-5000$ & 0.25 \\
\hline $1500-2500$ & 0 \\
\hline
\end{tabular}

Tabel 6. Tabel Penilaian Pedapatan

\begin{tabular}{|l|l|}
\hline \multicolumn{2}{|c|}{ Repayment Cap } \\
\hline$>3000$ & 1 \\
\hline $2001-30000$ & 0.75 \\
\hline $1501-2000$ & 0.5 \\
\hline $1001-1500$ & 0.25 \\
\hline $500-1000$ & 0 \\
\hline
\end{tabular}

\section{Metode Penelitian}

Menurut (Sugiyono, 2017), "Metode penelitian adalah cara ilmiah untuk mendapatkan data dengan tujuan dan 
kegunaan tertentu. Penelitian dilakukan untuk mendapat data-data yang valid dan dapat dibuktikan.

\section{Teknik Pengumpulan Data}

Menurut (Sugiyono, 2017), "Teknik pengumpulan data merupakan cara-cara yang dilakukan untuk memperoleh data dan keterangan-keterangan yang diperlukan dalam penelitian.

Teknik pengumpulan data yang dilakukan oleh penulis dalam melakukan pengumpulan data untuk pembuatan skripsi ini adalah:

1. Penelitian Lapangan (Field Research) Penelitian dilapangan adalah penelitian yang dimaksudkan untuk memperoleh data primer yaitu data yang diperoleh melalui:

a. Pengamatan (Observation)

Melalui metode ini penulis melakukan pengamatan langsung terhadap proses pemberian pembiayaan kredit yang sedang berjalan pada Koperasi Syariah BMT ItQan yang beralamat di Jl. Padasuka Atas No. 160, Pasirlayung, Cibeunying Kidul Bandung, guna memperoleh data dan informasi yang menunjang sistem baru.

b. Wawancara (Interview)

Dalam metode ini penulis mengumpulkan data dengan cara melakukan wawancara secara langsung kepada Bpk. Yanuar Permadi selaku Manajer HRD pada Koperasi Syariah BMT ItQan, guna mengetahui masalah yang berkaitan dengan pembangunan sistem, sistem baru yang diinginkan dan data serta informasi yang berhubungan dengan sistem baru.

2. Penelitian Kepustakaan (Library Research)

Dalam teknik ini penulis melakukan studi kepustakaan dengan berpedomankan pada buku dan jurnal yang berhubungan dengan studi literatur pada buku atau referensi yang berkaitan. Studi yang dilakukan penulis akan menghimpun informasi yang relevan dengan topik atau masalah yang sedang diteliti. Penulis melakukan pengambilan data dengan membaca dan mempelajari sistem tertulis mengenai sistem yang sedang berjalan pada Koperasi Syariah BMT ItQan dan juga sumber-sumber lain yang berhubungan dengan sistem pendukung keputusan.

3. Riset Internet (Online Research)

Dalam teknik ini penulis melakukan pengumpulan dan pengambilan data yang berasal dari situs-situs atau website yang berhubungan dengan berbagai informasi yang dibutuhkan dalam penelitian yang diteliti, serta artikel-artikel penunjang yang didapatkan dari internet.

\section{Hasil dan Pembahasan}

\subsection{Analisa Kebutuhan Software}

Tahap ini merupakan tahapan analisa kebutuhan yang dilakukan setelah sebelumnya melakukan analisa pada sistem yang sedang berjalan di Koperasi Syariah bmt itQan, analisa kebutuhan bertujuan untuk menentukan langkah pembuatan perangkat lunak yang baik dan sesuai dengan kebutuhan pengguna yang akan digunakan nantinya dalam mempermudah pekerjaannya.

\section{A. Tahapan Analisis}

Sistem pendukung keputusan kelayakan pembiayaan berbasis web ini merupakan sebuah sistem baru pada proses pembiayaan yang akan dibangun pada Koperasi Syariah bmt itQan. Tujuan dari pembangunan sistem ini adalah untuk mempermudah dalam melakukan analisa terhadap pembiayaan yang diajukan oleh anggota. Sistem ini akan membantu manajer dalam mengambil keputusan terhadap kelayakan pembiayaan, beberapa kebutuhan untuk membangun sebuah sistem pendukung keputusan yang dapat menghitung beberapa alternatif dan 
mendapatkan nilai akhir dari alternatif tersebut. Tahapan analisis dari pembuatan sistem informasi ini adalah:.

Kebutuhan Manajer :

A1. Manajer dapat melakukan login.

A2. Manajer dapat mengelola data pemohon.

A3. Manajer dapat mengelola bobot kriteria

A4. Manajer dapat mengelola data alternatif.

A5. Manajer dapat mengelola nilai matriks.

A6. Manajer dapat melihat hasil-hasil perhitungan topsis.

A7. Manajer dapat melihat keputusan dan mencetak laporan hasil topsis.

\section{B. Use Case Diagram}

Use case diagram di buat agar pengguna aplikasi dapat memahami proses yang diusulkan dalam pembuatan aplikasi berbasis web. Use case diagram yang di buat berada pada level user Manajer. Berikut merupakan gambaran use case diagram SPK yang diusulkan :

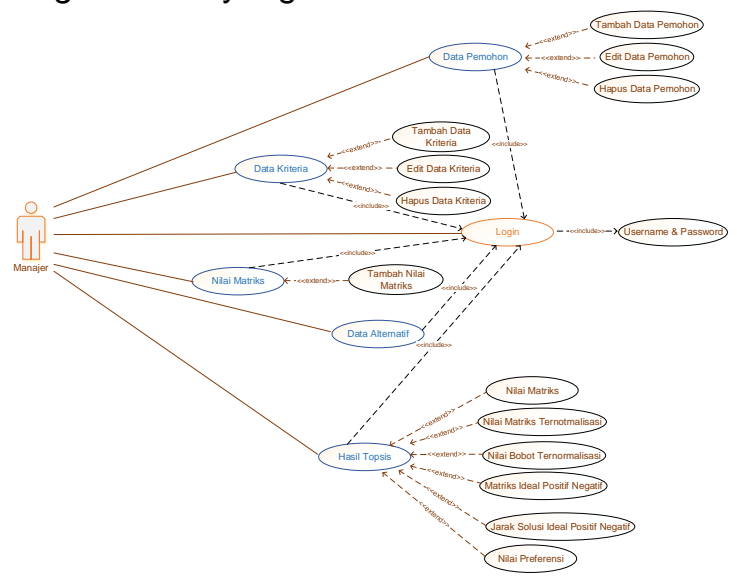

Gambar 1. Use Case Diagram

\subsection{Desain}

Pada tahap desain akan menjelaskan mengenai desain database, desain software architecture dan desain user interface dari aplikasi atau sistem yang dibuat.

Database atau basis data adalah kumpulan data yang saling berelasi. Data sendiri merupakan fakta mengenai objek, orang, dan lain-lain. Data dinyatakan dengan nilai (angka, deretan katakter, atau simbol). Basis data bertujuan mengatur data sehingga diperoleh kemudahan, ketepatan, dan kecepatan dalam pengolahan data (Jatnika, 2013). Berikut penggambaran desain konseptual suatu basis data yang menggambarkan relasi antar entitas, yang digambarkan dengan entity relationship diagram, logical record structure dan spesifikasi file:

A. Entity Relationship Diagram

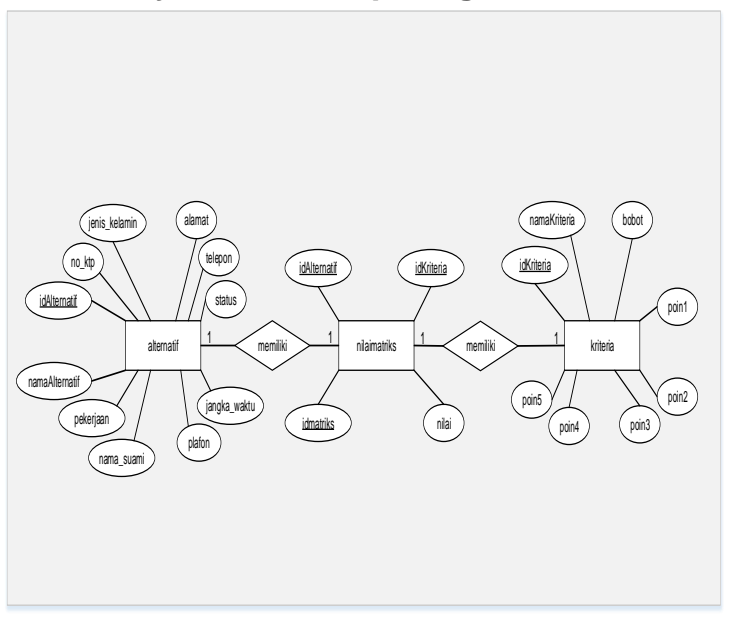

Gambar 2. Entity Relationship Diagram

B. Logical Record Structure

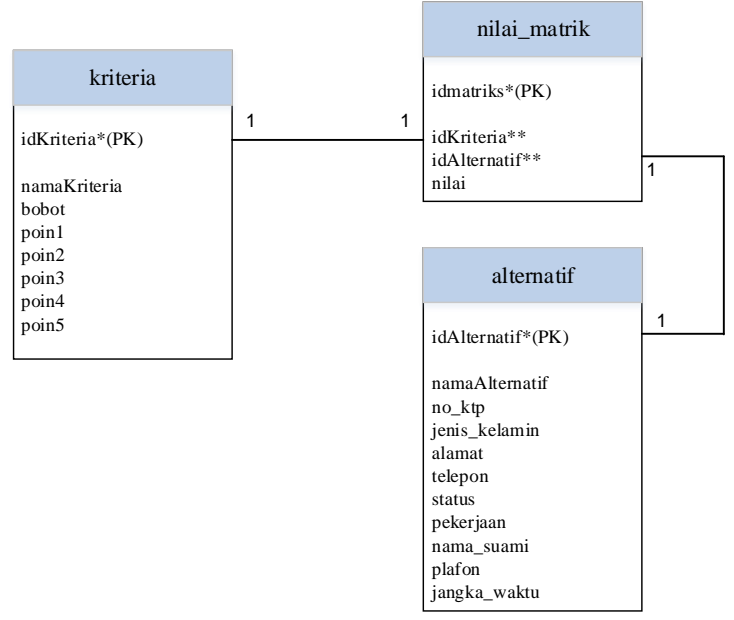

Gambar 3. Logical Record Structure

Software Architecture

Tahapan ini menjelaskan penggambaran component diagram dan deployment diagram. 


\section{A. Component Diagram}

Component Diagram dibuat untuk menunjukan organisasi dan ketergantungan diantara kumpulan komponen dalam sebuah sistem.

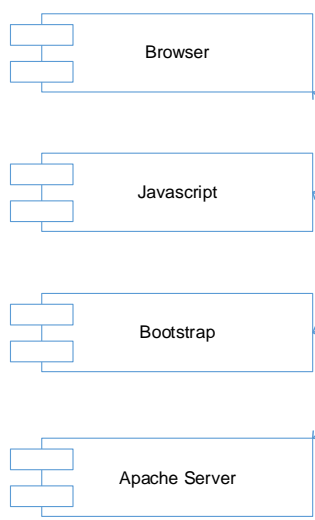

Mysql Database

\section{Gambar 4. Component Diagram}

\section{B. Deployment Diagram}

Deployment diagram menunjukan konfigurasi komponen dalam proses eksekusi aplikasi.

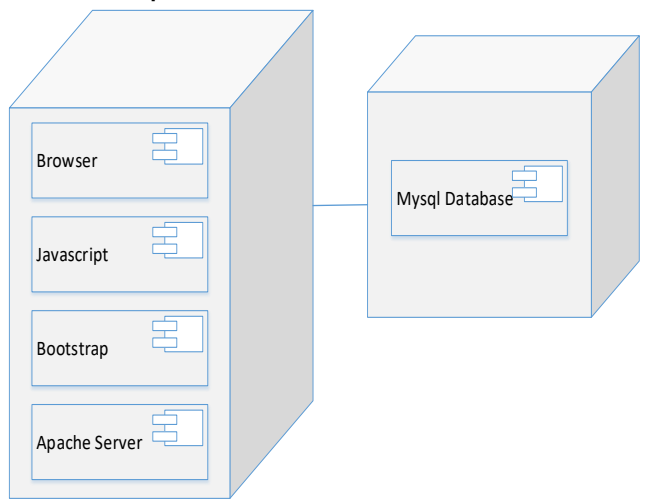

Gambar 5. Deployment Diagram

\section{User Interface}

User interface merupakan gambar anatarmuka dari perancangan sistem yang dibuat. Perancangan antarmuka berfungsi untuk memudahkan interaksi antara pengguna dengan sistem.

\section{Halaman Login Manajer}

Halaman login manajer merupakan salah satu antarmuka yang disediakan untuk interaksi manajer dengan sistem agar dapat mengakses menu utama dari aplikasi. Berikut gambar user interface login manajer:

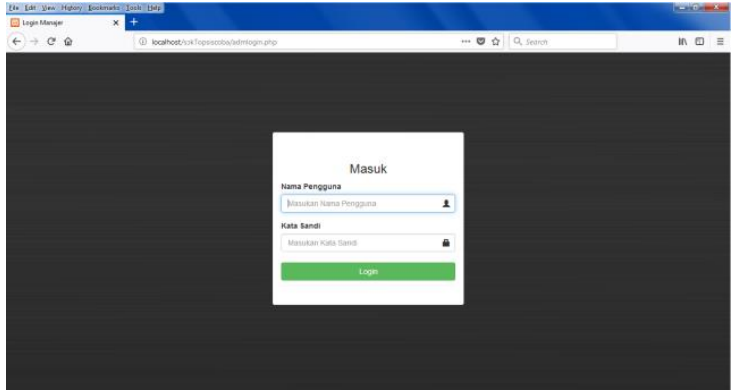

\section{Gambar 6. Tampilan Halaman Login Manajer}

\section{Menu Data Pemohon}

Menu data pemohon merupakan menu bagi manajer untuk dapat melihat data pemohon, mengisi atau menambahkan data pemohon, mengubah data pemohon dan menghapus data pemohon.

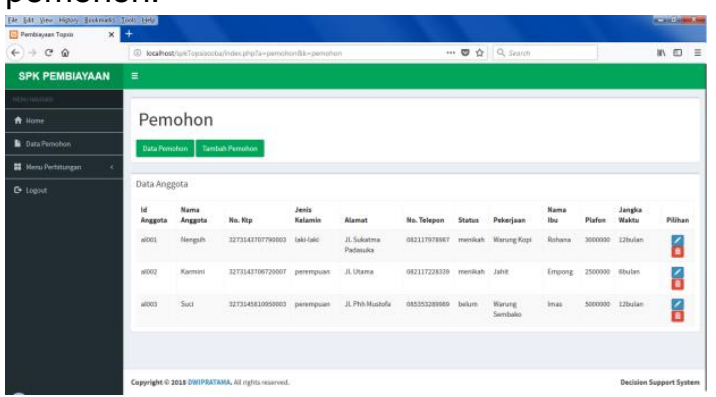

\section{Gambar 7. Tampilan Menu Data Pemohon}

\section{Menu Data Kriteria}

Menu data kriteria merupakan menu bagi manajer untuk dapat melihat data kriteria, mengisi atau menambahkan data kriteria, mengubah data kriteria dan menghapus data kriteria.

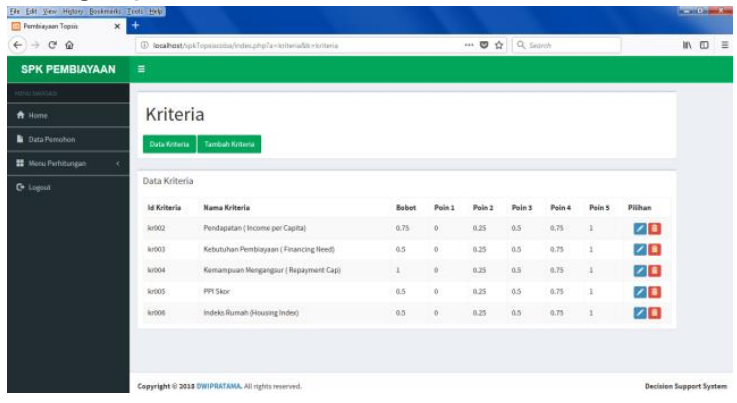

\section{Gambar 8. Tampilan Menu Data Kriteria}

\section{Menu Data Alternatif}

Menu data alternatif merupakan menu bagi manajer untuk dapat melihat 
data alternatif, data alternatif didapatkan berdasarkan data pemohon.

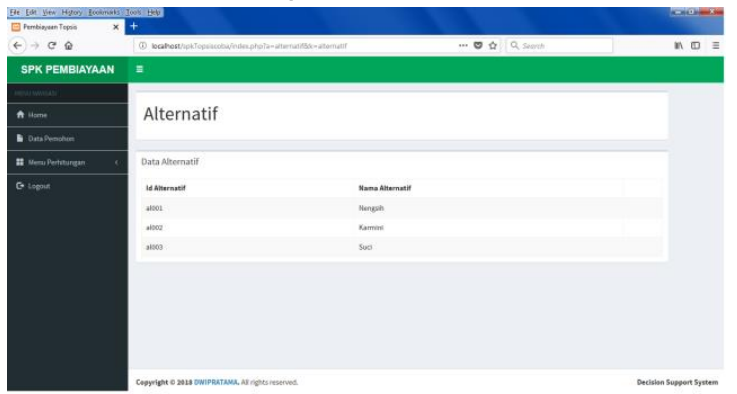

Gambar 9. Tampilan Menu Data Alternatif

\section{Menu Input Nilai Matriks}

Menu nilai matriks merupakan menu bagi manajer untuk dapat melihat data mengisi atau menambahkan nilai matris dan mengubah nilai matriks.

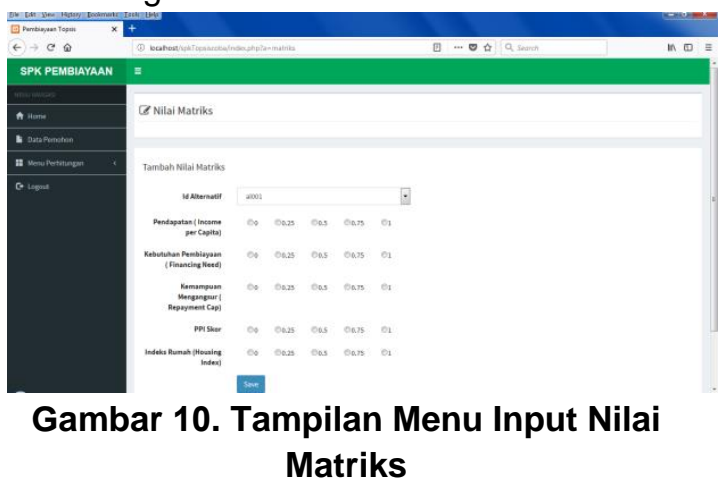

\section{Menu Nilai Matriks}

Menu nilai matriks merupakan menu bagi manajer untuk dapat melihat data nilai matriks.

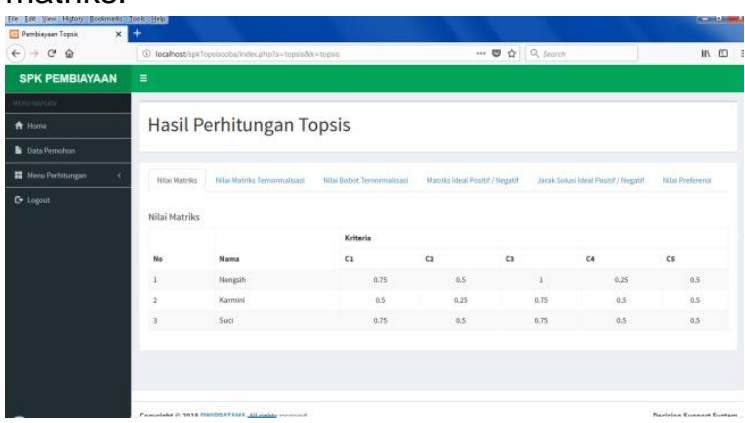

Gambar 11. Tampilan Menu Nilai Matriks

\section{Menu Nilai Matriks Ternormalisasi}

Menu nilai matriks ternormalisasi merupakan menu bagi manajer untuk dapat melihat data nilai matriks ternormalisasi.

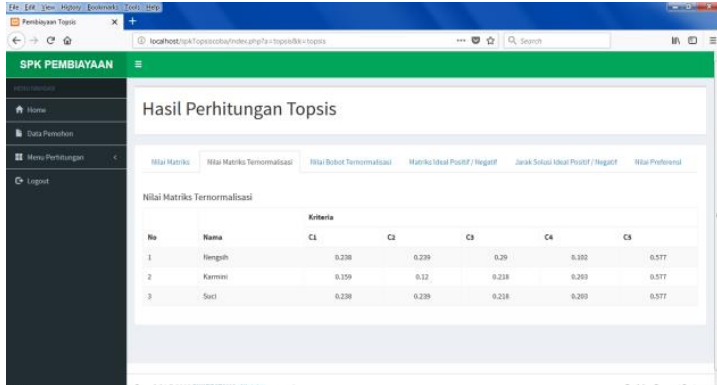

Gambar 12. Tampilan Menu Nilai Matriks Ternormalisasi

\section{Menu Nilai Bobot Ternormalisasi}

Menu nilai bobot ternormalisasi erupakan menu bagi manajer untuk dapat melihat data nilai bobot ternormalisasi.

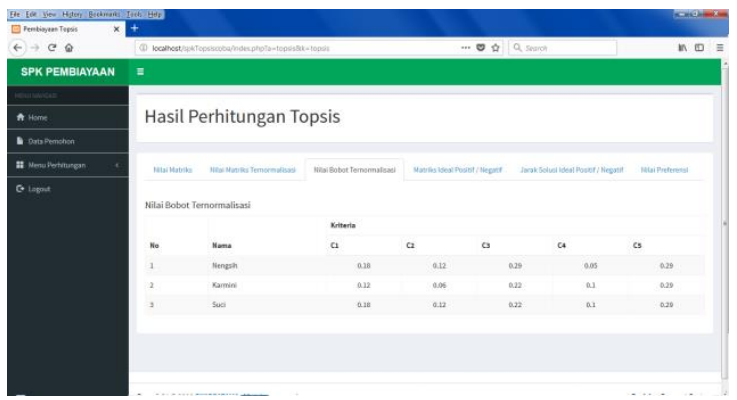

\section{Gambar 13. Tampilan Menu Nilai Bobot Ternormalisasi}

\section{Menu Nilai Matriks Ideal Positif Negatif}

Menu nilai matriks ideal positif negatif merupakan menu bagi manajer untuk dapat melihat matriks ideal positif negatif.

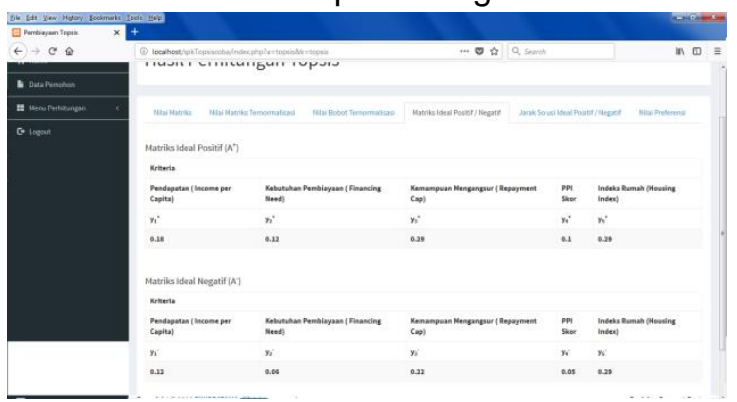

Gambar 14. Tampilan Menu Nilai Matriks Ideal Positif Negatif

\section{Menu Nilai Jarak Solusi Ideal} Positif Negatif

Menu nilai jarak solusi ideal positif negatif merupakan menu bagi manajer untuk dapat melihat data nilai jarak solusi ideal positif negatif. 


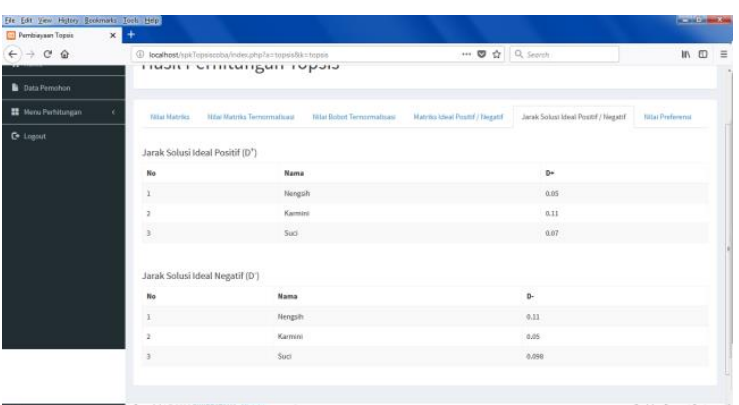

Gambar 15. Tampilan Menu Nilai Jarak Solusi Ideal Positif Negatif

\section{Menu Nilai Preferensi}

Menu nilai preferensi merupakan menu bagi manajer untuk dapat melihat data nilai preferensi.

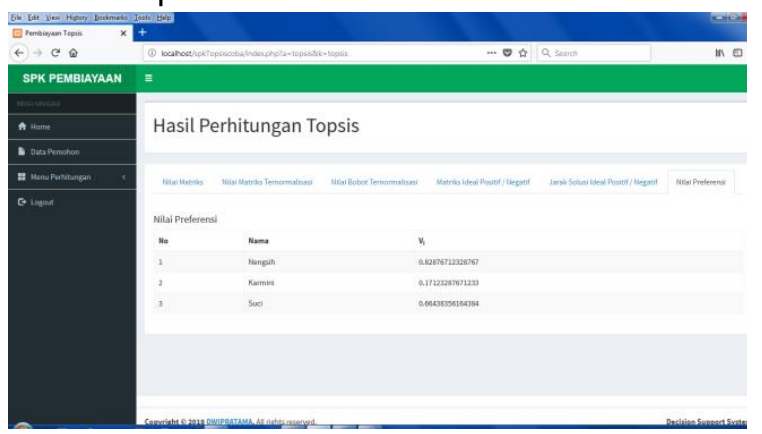

Gambar 16. Tampilan Menu Nilai preferensi

\section{Kesimpulan}

Berdasarkan hasil penelitian yang telah penulis lakukan pada Koperasi Syariah Bmt itQan, terdapat pokok permasalahan yang penulis dapatkan, yaitu mengenai penentuan pemberian pembiayaannya perhitungan yang masih dilakukan dengan menggunakan banyak berkas secara manual, apabila terjadi perubahan data atau informasi maka diperlukan waktu yang tidak sebentar, sehingga keputusan yang dihasilkan masih kurang efektif dan akurat karena terkadang ada beberapa kriteria yang tidak ikut dipertimbangkan pada saat proses penilaian. Maksud yang ingin disampaikan penulis berdasarkan hasil Berdasarkan hasil penelitian yang telah penulis lakukan pada Koperasi Syariah Bmt itQan adalah menyarankan menggunakan aplikasi pendukung keputusan untuk membantu pemberian pembiayaan agar hasil keputusan lebih akurat dan objektif. Dari hasil pembahasan tentang Sistem Pendukung Keputsan kelayakan pemberian pembiayaan pada Koperasi Syariah Bmt itQan makan dapat diambil kesimpulan diantaranya:

1. Dapat menghasilkan suatu sistem pendukung keputusan pemberian pembiayaan kredit pada Koperasi Syariah bmt ItQan.

2. Dapat memberikan manfaat bagi pihak koperasi, karena dengan adanya sistem pendukung keputusan akan menghasilkan laporan data pemberian pembiayaan yang akurat sangat membantu dalam pemberian pembiayaan pada Koperasi Syariah bmt ItQan.

3. Penerapan metode TOPSIS pada sistem yang dibuat, didesain untuk memecahkan masalah yang terukur bagi sistem pendukung keputusan kelayakan pembiayaan kelayakan pembiayaan. Sehingga penilaian bersifat lebih objektif.

\section{Referensi}

Fathansyah. (2012). Basis Data. Bandung: Informatika.

Ferdiansyah, N., Bachri, O. S., \& Harliana. (2015). Sistem Pendukung Keputusan Penentuan Prioritas Prioritas Perbaikan Jalan di Dinas Bina Marga Kabupaten Cirebon dengan Metode TOPSIS, 6-8.

Hasugian, H., \& Shidiq, A. N. (2012). Rancang Bangun Sistem Informasi Industri Kreatif Bidang Penyewaan Sarana Olahraga. Seminar Nasional Teknologi Informasi Dan Komunikasi Terapan (Semantik) 2012, 2012(Semantik), 606-612. Retrieved from http://eprints.dinus.ac.id/202/

Jatnika, H. (2013). Pengantar Sistem Basis Data Memahami Konsep Dasar \& Tuntunan Praktis Perancangan Database. Yogyakarta: Andi.

Jusuf, J. (2014). Analisis Kredit untuk Account Officer. Jakarta: Pt. Gramedia.

Kadir, A. (2014). Pengenalan Sistem Informasi (Edisi Revi). Yogyakarta: Andi. 
Kashmir. (2014). Bank dan Lembaga Keuangan Lainnya (Edisi Revi). Jakarta: PT. Raja Grafindo Persada.

Kristiana, T. (2018). Sistem Pendukung Keputusan Dengan Menggunakan Metode TOPSIS Untuk Pemilihan Lokasi Pendirian Grosir Pulsa. Paradigma, $X X$, No.1(1), 8-12.

Kristiyanti, D. A. (2017). Sistem Pendukung Keputusan Seleksi Karyawan Untuk Jabatan Tertentu Dengan Pendekatan Analisa Gap Profile Matching. Jurnal Paradigma, 19(1), 20-29.

Listiyono, H., Sunardi, \& Khristianto, T. (2011). Rekayasa Perangkat Lunak Sistem Pendukung Keputusan Pemberian Kredit( Studi Kasus pada BPR Argo Dana Semarang ). Jurnal Teknologi Informasi DINAMIK, 16(1), 72-76.

Mardiana, T. (2017). Penerapan Algoritma Topsis dalam Sistem Pendukung Keputusan Pemberian Pinjaman Pada Koperasi Karyawan. Jurnal Khatulistiwa Informatika, V(2), 128138.

Mubarok, A., \& Rosmiati, A. (2016). Sistem penunjang keputusan prioritas perbaikan jalan menggunakan metode analytical hierarchy process. Informatika, 3(September), 200-207. Retrieved from http://ejournal.bsi.ac.id/ejurnal/index.p $\mathrm{hp} / \mathrm{j} /$ article/view/818

Mulyadi. (2016). Sistem Akuntansi. Jakarta Selatan: Salemba Empat.

Nugroho, B. (2013). Dasar Pemrograman Web PHP - MySQL dengan Dreamweaver. Yogyakarta: Gava Media.
Nuris, N. (2017). Sistem Keputusan Metode Saw Dan Topsis Untuk Pemilihan Staff Peduli Laka Studi Kasus: Pt Express Pool Cipayung. Evolusi, 5(2), 2338-8161. Retrieved from https://ejournal.bsi.ac.id/ejurnal/index. php/evolusi/article/view/2599

Rosa, A., \& Shalahuddin, M. (2014). Rekayasa Perangkat Lunak Struktur dan Berorientasi Objek. Bandung: Informatika.

Rudianto. (2010). Akuntansi Koperasi. Jakarta: Erlangga.

Saputro, M. I., \& Mardiana, T. (2015). Agen Cerdas untuk Penentuan Kelayakan Pemberian Kredit Koperasi Simpan Pinjam, I(2), 245-252.

Sudradjat, B. (2017). Pemberian Kredit Pada Koperasi Menggunakan Metode Profile Matching, 4(2), 183-188.

Sumanto, \& Marita, L. S. (2017). Fuzzy Simple Additive Weighting ( Fsaw ) Untuk Analisa Kelayakan Pemberian Kredit Mobil, 2(2), 1-13.

Sutabri, T. (2012). Analisis Sistem Informasi. Yogyakarta: Andi.

Umam, K. (2016). Perbankan Syariah: Dasar-dasar dan Dinamika Perkembangan Di Indonesia. Jakarta: PT. Raja Grafindo Persada.

Wingdes, I., \& Widayanti, T. (2017). Penerapan AHP dan Topsis untuk Penilaian Kelayakan Kredit Pada BPR Centradana Kapuas Pontianak, 10(2), 255-268. 